Western University

Scholarship@Western

Aboriginal Policy Research Consortium International (APRCi)

2012

\title{
Preliminary development and content validity of a measure of Australian Aboriginal cultural engagement
}

Stacey L. Berry

Trevor P. Crowe

Frank P. Deane

Follow this and additional works at: https://ir.lib.uwo.ca/aprci

Part of the Psychiatric and Mental Health Commons, and the Substance Abuse and Addiction Commons

Citation of this paper:

Berry, Stacey L.; Crowe, Trevor P.; and Deane, Frank P., "Preliminary development and content validity of a measure of Australian Aboriginal cultural engagement" (2012). Aboriginal Policy Research Consortium International (APRCi). 348.

https://ir.lib.uwo.ca/aprci/348 
This article was downloaded by: [University of Western Ontario]

On: 28 July 2012, At: 07:42

Publisher: Routledge

Informa Ltd Registered in England and Wales Registered Number: 1072954 Registered

office: Mortimer House, 37-41 Mortimer Street, London W1T 3J H, UK

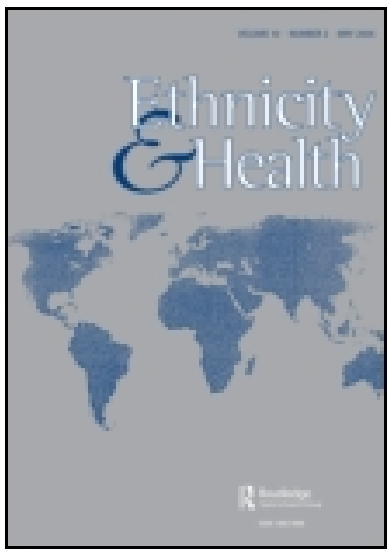

\title{
Ethnicity \& Health
}

Publication details, including instructions for authors and subscription information:

http:// www.tandfonline.com/loi/ ceth20

\section{Preliminary development and content validity of a measure of Australian Aboriginal cultural engagement}

\author{
Stacey L. Berry ${ }^{a}$, Trevor P. Crowe ${ }^{a} \&$ Frank P. Deane ${ }^{a}$ \\ a Illawarra Institute for Mental Health, University of Wollongong, \\ Building 22, NSW, 2522, Australia \\ Version of record first published: $06 \mathrm{~J}$ an 2012
}

To cite this article: Stacey L. Berry, Trevor P. Crowe \& Frank P. Deane (2012): Preliminary development and content validity of a measure of Australian Aboriginal cultural engagement, Ethnicity \& Health, 17:3, 325-336

To link to this article: http:// dx.doi.org/ 10.1080/ 13557858.2011.645157

\section{PLEASE SCROLL DOWN FOR ARTICLE}

Full terms and conditions of use: http://www.tandfonline.com/page/terms-andconditions

This article may be used for research, teaching, and private study purposes. Any substantial or systematic reproduction, redistribution, reselling, loan, sub-licensing, systematic supply, or distribution in any form to anyone is expressly forbidden.

The publisher does not give any warranty express or implied or make any representation that the contents will be complete or accurate or up to date. The accuracy of any instructions, formulae, and drug doses should be independently verified with primary sources. The publisher shall not be liable for any loss, actions, claims, proceedings, demand, or costs or damages whatsoever or howsoever caused arising directly or indirectly in connection with or arising out of the use of this material. 


\title{
RESEARCH ARTICLE
}

\section{Preliminary development and content validity of a measure of Australian Aboriginal cultural engagement}

\author{
Stacey L. Berry*, Trevor P. Crowe and Frank P. Deane \\ Illawarra Institute for Mental Health, University of Wollongong, Building 22, NSW 2522, \\ Australia
}

(Received 11 May 2011; final version received 11 November 2011)

\begin{abstract}
Objectives. Aboriginal people form one of the populations most in need of mental health and substance abuse services within Australia, although many services are not adequately sensitive to, or inclusive of, relevant aspects of Aboriginal culture in their programmes. The Aboriginal Cultural Engagement Survey (ACES) was developed with the objective of assessing the level of cultural engagement of Aboriginal clients. A measure of cultural engagement is an important step in establishing an association between culture and health benefits, so that future interventions may be designed which better meet the cultural needs of Aboriginal Australians within health services.

Design. The process of development of the ACES involved four stages of scale development utilising a series of group discussions and reviews with Aboriginal consultants. Assessment of content validity is conducted using the Content Validity Index (CVI).

Results. The ACES was found to have excellent content validity with CVIs over 0.80 for all items in the final version.

Conclusion. The ACES shows promise for being a useful tool in assessing the cultural engagement of Australian Aboriginal clients. There is a need for further psychometric assessment and field trials to assess its utility.
\end{abstract}

Keywords: Aboriginal; Australian; culture; engagement; health outcomes; content validity

\section{Introduction}

\section{Theoretical background and population}

Since the colonisation of Australia, Aboriginal Australians have experienced extreme levels of disempowerment, loss of identity, grief and cultural alienation (Hunter 1993), resulting from many years of systematic assault on their traditional practices, languages and cultures (Leenaars et al. 1999). This has had a devastating impact on the physical and mental health of Aboriginal Australians (Cleworth et al. 2006), and as a result there is a significant need for health services within this population. Despite this, there is evidence that Aboriginal Australians do not access health services at a level consistent with their level of need (Westerman 2004), and it has been suggested that a major factor contributing to this is the lack of culturally appropriate services available for Aboriginal individuals (Berry and Crowe 2009).

*Corresponding author. Email: slb775@uowmail.edu.au 
Many Aboriginal Australians report a strong connection to their culture. A significant part of this culture, and an important factor in Aboriginal conceptualisations of mental health, is the holistic nature of health and well-being (Ypinazar et al. 2007). Pat Anderson (1996, p. 15), in her former role as the chairperson of the National Aboriginal Community Controlled Health Organisation, states that for Aboriginal people 'our identity as human beings remains tied to our land, to our cultural practices, our systems of authority and social control, our intellectual traditions, our concepts of spirituality, and to our systems of resource ownership and exchange. Destroy this relationship and you damage - sometimes irrevocably individual human beings and their health'. Furthermore, it is believed that the degree to which an individual is embedded in his/her cultural traditions plays a vital protective function in mental health and substance abuse (Torres Stone et al. 2006).

Cultural engagement refers to the degree to which an individual is embedded within his/her cultural traditions. When referring to Aboriginal Australians, cultural engagement includes a wide variety of activities, some examples of which are traditional cooking practices, use and protection of land and Country, traditional artwork, music and dance, and participation in community practices (e.g., ceremony, meetings). Cultural engagement also involves an attitude of respect for others and community belonging, which although difficult to define and capture, was noted by many participants involved in the present research as being a significant component of Aboriginal culture.

There is a commonly held belief that engagement in cultural activities is beneficial for Aboriginal Australians (Morice 1976, O'Dea 1984, McDermott et al. 1998, Burgess et al. 2008, Rowley et al. 2008), particularly so for those individuals who highly value their cultural traditions. Caring for Country refers to caring for one's homeland and comprises one aspect of cultural engagement for Aboriginal Australians. Caring for Country has been defined as having the knowledge and responsibility to manage traditional lands, and the participation of Aboriginal Australians in 'interrelated activities with the objective of promoting ecological and human health' (Burgess et al. 2008, p. 1). There is preliminary evidence that cultural engagement can lead to positive health benefits for Aboriginal Australians. Caring for Country has been associated with health benefits for Aboriginal Australians such as building self-esteem, fostering self-identity and enabling relaxation through contact with the natural environment (Kingsley et al. 2009). Research has also found that Aboriginal people living in homelands, where traditional practices of Caring for Country are common, have better health outcomes than those in centralised populations (Morice 1976, O’Dea 1984, McDermott et al. 1998, Burgess et al. 2008, Rowley et al. 2008). Rowley et al. (2008) investigated health outcomes in the Utopia community, a decentralised community in Australia's Northern Territory, over a 10-year period. They measured mortality from all causes as well as mortality and hospitalisations associated with cardiovascular disease, and found rates to be 40-50\% lower within the Utopia community than within the general Northern Territory Aboriginal population. It was argued that the positive health outcomes in this community were likely to be related to connectedness to culture, family and land. Similarly, Aboriginal people living on homelands in Central Australia had significantly better health outcomes with regard to mortality, hospitalisation, hypertension, diabetes and injury than those living in centralised areas (McDermott et al. 1998). O'Dea (1984) found marked health improvements in Australian 
Aboriginal people with diabetes after a temporary reversion to traditional lifestyle. However, it should be noted that based on the results of these previous studies, it is unclear whether the reason for the health gains evidenced is cultural engagement itself, or perhaps the effects of being with family, living an active lifestyle or any number of other variables which may affect health in a positive way. Although the relationship between cultural engagement and positive health outcomes is often implied, there is a need to more directly measure engagement in cultural activities and its subsequent impact on health outcomes.

Torres-Stone et al. (2006) developed a measure of cultural engagement to evaluate the relationship between alcohol cessation and engagement in traditional activities amongst American Indians. They found that participation in traditional activities and traditional spirituality had significant positive effects on alcohol cessation. Such a comprehensive measure of cultural engagement does not yet exist for Aboriginal Australians. The Caring for Country Questionnaire (Burgess et al. 2008) measures some activities which are related to Aboriginal cultural engagement (e.g., spending time on Country, protecting Country, ceremony), however it does not adequately capture the wider variety of activities which represent cultural engagement for Aboriginal Australians. A more comprehensive measure of cultural engagement is needed to clarify whether there is an association between cultural engagement and health benefits for Aboriginal Australians.

It should be noted that much care has been taken in the development of this survey to avoid subscribing to the cultural deficit model with regard to Aboriginal health. The cultural deficit model is concerned with explaining why a minority group may not have adopted the behaviours and values of the majority group (Kirk and Goon 1975), and cultural deficit thinking can often be used to hold minority groups responsible for their own disadvantage, whether it is in terms of education, poverty or health. For example, Johnson and Bowman (2003) explain that African-American people have been judged as holding themselves in a cycle of poverty because they have a poverty of culture, including poor values, attitudes and motivation. In contrast, the current study aims to explore the premise that engagement in cultural activities for Aboriginal people will vary in terms of diversity and complexity, and may or may not be associated with health outcomes. It is not expected that the entirety of Aboriginal culture will be embodied in this survey, and it is in no way suggested that a low level of engagement as measured by this survey equates to a deficit of culture. The Commonwealth Commission on Respect and Understanding in 2007 states that groups may have difficulty understanding each other when a single component of cultural identity is prioritised, and individuals no longer have the option to choose which elements of their identity they emphasise (Commonwealth Secretariat 2007). It is expected that there are many diverse possibilities for expression of Aboriginal cultural identity, and individuals are likely to express their Aboriginality in unique ways. Including a variety of types of activities, both concrete and abstract/ideological components of culture, and seeking information during scale development from individuals from a variety of tribal and language groups, this survey is designed to capture a varied expression of cultural identity. However, it is expected that there will be individuals for whom this survey does not fully represent the ways they engage with their culture. A caveat must be made that while this survey measures aspects of Aboriginal cultural activity, it does not measure 'Aboriginality' or 'cultural goodness'. 
Some may argue whether cultural engagement can actually be captured by a questionnaire, due to its dynamic and conditional nature. Culture is an everchanging construct, the understanding of which varies according to group membership, individual belief structures and time-related perspectives. During the process of this survey's development there were certainly critics who suggested that culture cannot be captured by words on a page. The authors appreciate that culture is too complex for such an exercise, and this survey does not purport to measure culture in totality or in an absolute manner. It simply aims to provide services and individuals themselves with information regarding the type and extent of cultural activities undertaken. Furthermore, the very changing nature of culture is one of the primary reasons this survey's development is important. With the significant intrusion made on Australian Aboriginal culture over the past centuries, Aboriginal culture has become difficult to define and experience for Aboriginal and non-Aboriginal people alike. This survey provides an opportunity to capture a snapshot of particular dimensions of culture, at a particular point in time, with a particular group of Aboriginal Australians. The survey does not attempt to limit what is considered culture over time, and it is likely that in the future it will be important to repeat some of the procedures used in this study to see whether perspectives have changed. The approach used in the present study is one of consultation with individuals within the cultural group, and this would be encouraged to continue over time. There is currently very little knowledge and understanding about what constitutes Australian Aboriginal culture in a modern reality, and the developed measure provides a structured and reliable method of gathering information regarding the extent to which individuals engage in particular cultural activities.

\section{Need for the instrument}

Anecdotal reports from young Aboriginal Australians indicate they have difficulty articulating a sense of cultural connection. This has been attributed to a lack of open cultural practice and systemic cultural transmission by older Aboriginal people. Enhancing connection with a traditional culture which is diminishing and often inaccessible presents a difficult task. However, culture is not a static thing but one which changes over time, and as such there is a need for a measure of cultural engagement for Aboriginal Australians which is relevant to the lifestyle, traditional knowledge and challenges of today's Aboriginal people. A reliable and valid measure of cultural engagement will allow future research to establish whether there is a clear association between cultural engagement and health benefits. Establishing a link between cultural engagement and positive health outcomes will then provide a theoretical basis for the inclusion of culture in treatment planning and programme development. Such an inclusion of culture in assessment, treatment and programme development is hoped to foster significant health benefits for Aboriginal clients within Australian health services.

\footnotetext{
Aims

The present research aims to develop a comprehensive and psychometrically sound measure of cultural engagement for Aboriginal Australians. The research subsequently aims to determine preliminary content validity of the new measure.
} 


\section{Methods}

\section{Development of the instrument}

Figure 1 outlines the stages of development. All stages of validation of this instrument occurred within a semi-urban population in the Illawarra and South Coast regions of New South Wales, Australia.

Stage one involved development of the first version of the survey based on items from the Caring for Country Questionnaire (Burgess et al. 2008), Multigroup Ethnic Identity Measure (MEIM: Phinney 1992) and the Sense of Culture Yarn (Westerman 2008). This process was also informed by discussions with four Aboriginal individuals employed with Aboriginal substance abuse services, the Aboriginal Health and Medical Research Council, the Aboriginal Medical Service and the University of Wollongong, Department of Indigenous Studies. As a preliminary step prior to disseminating a draft survey to consultants in stage two, the four discussants provided a varied base of opinion, reviewed the items and made suggestions for changes in wording and additional items. These consultants were approached over a period of three weeks and were chosen based on their expertise in Aboriginal cultural issues evident in their professional work. They were presented with a draft of questions derived from the measures listed earlier and were asked to comment generally on the appropriateness and relevance of the questions to Aboriginal cultural engagement. Responses were collected in an informal interview with the primary researcher, and the consultants' suggestions were used to amend existing questions and form additional questions, resulting in version one of the survey. Version one comprised 18 items answered on the same four-point Likert scale used in the Caring for Country Questionnaire; not at all (none), a little (a few days in the year), a fair bit (a few weeks in the year) and a lot (a few months in the year) (Burgess et al. 2008).

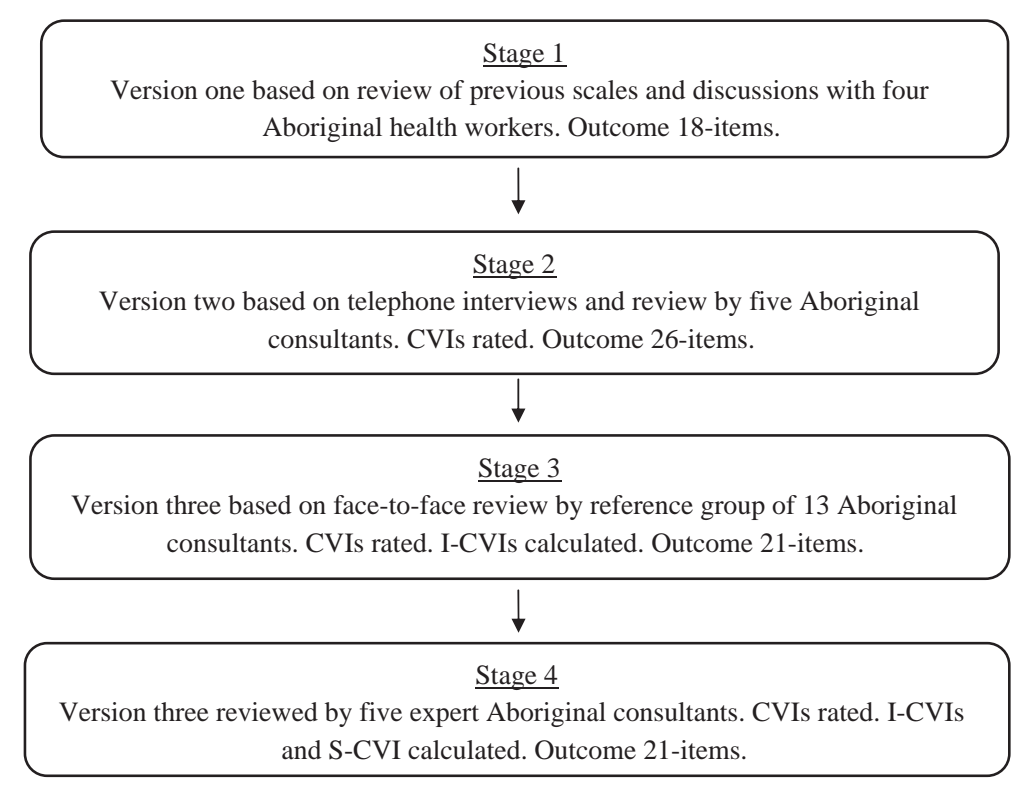

Figure 1. Stages of development of the Aboriginal Cultural Engagement Survey (ACES). 
Stage two involved providing a copy of the 18 -item version one measure to five consultants who were then interviewed by telephone. The consultants comprised four males and one female, including three managers of remote Aboriginal substance abuse services, one Aboriginal drug and alcohol worker and one member of staff from the Aboriginal Health and Medical Research Council (the latter consultant was also involved in the discussions in stage one). Five consultants were chosen for stage two to improve on the participant numbers in stage one and to provide an intermediate step between the initial discussions and the reference group in stage three. Consultants were again selected based on their expertise in Aboriginal cultural issues demonstrated in their professional work. The telephone interview required consultants to respond to the items in version one of the survey and to rate each item on a Content Validity Index (CVI; see Measures section), that involved rating each item in terms of its relevance to Aboriginal cultural engagement. Consultants were asked to comment on the appropriateness of the items, suggest any changes they thought necessary and suggest any additional items they believed should be included. This process resulted in some minor changes in wording of the existing items, and the addition of eight new items. Consequently version two included a total of 26 items, rated on the same Likert scale, which is included in the left side of Table 1.

Stage three. Thirteen Aboriginal consultants attended a reference group. Potential consultants were informed of the reference group via advertisements distributed through local services, and consultants with specific cultural expertise (e.g., community Elders, Aboriginal cultural workers) were contacted by telephone and email. Potential consultants included Aboriginal staff members of substance abuse services, staff members of Aboriginal health services, community Elders accessed through local services and community members accessed through local services and word-of-mouth. Eighteen consultants were invited to attend the reference group with the expectation that not all who were invited would be available to attend, and with the hope that 10-15 consultants would provide a robust yet manageable selection of consultants. The resulting reference group included 13 consultants (11 females and two males), comprising one staff member of an Aboriginal substance abuse service, three staff members of the Aboriginal Medical Service, four local community Elders and five community members. One member of the reference group was also involved in the discussion in stage one. All consultants responded to the 26 items in version two of the survey, as well as rating each item on a CVI. A group discussion was held in which consultants commented and made suggestions regarding the items. An item level CVI (I-CVI; see Measures section) was calculated for each item based on the ratings from the telephone interviews and the reference group. Review of the I-CVI along with suggestions from the reference group resulted in several items being revised, deleted or added. A third and final version of the survey resulted from this process, and this is included in the right side of Table 1.

Stage four. Five expert consultants (three females and two males) were asked to complete a CVI for each item on the final version of the survey. Five experts were sought following recommendations of Polit et al. (2007), who suggest that 3-5 experts should provide ratings for the second round of CVI calculations. Three of the five experts were selected from the consultants in stage three, the fourth expert was involved in stage one and stage two and the fifth expert was a consultant in stage two. They were identified as experts based on their engagement with the community at different levels (e.g., as Elders, community representatives) and were seen to 
Table 1. Items and their CVIs used in the development of the Aboriginal Cultural Engagement Survey (ACES).

\begin{tabular}{|c|c|c|c|c|c|}
\hline Item & Items in version two & CVI & $\begin{array}{l}\text { New } \\
\text { item }\end{array}$ & $\begin{array}{c}\text { Amendments made (Version } \\
3 \text { - Aboriginal Cultural } \\
\text { Engagement Survey) }\end{array}$ & CVI \\
\hline 1 & $\begin{array}{l}\text { I spend time trying to learn about } \\
\text { my Aboriginal culture, such as its } \\
\text { history, traditions and customs }\end{array}$ & 0.94 & 1 & $\begin{array}{l}\text { Unchanged - I spend time trying } \\
\text { to learn about my Aboriginal } \\
\text { culture, such as its history, } \\
\text { traditions and customs }\end{array}$ & 1.00 \\
\hline 2 & $\begin{array}{l}\text { I speak my traditional Aboriginal } \\
\text { language (including pidgin, } \\
\text { creole and Aboriginal terms) }\end{array}$ & 0.67 & & Removed & \\
\hline 3 & $\begin{array}{l}\text { I make traditional artworks (e.g., } \\
\text { painting, weaving, carving) }\end{array}$ & 0.78 & 2 & $\begin{array}{l}\text { I make Aboriginal artworks (e.g., } \\
\text { painting, weaving, carving) }\end{array}$ & 0.80 \\
\hline 4 & $\begin{array}{l}\text { I participate in Aboriginal } \\
\text { cultural practices of food } \\
\text { preparation (e.g., bush meats, } \\
\text { dampers, Johnny cakes) }\end{array}$ & 0.78 & 3 & $\begin{array}{l}\text { I participate in traditional } \\
\text { Aboriginal practices of food } \\
\text { preparation (e.g., bush meats, } \\
\text { dampers, Johnny cakes) }\end{array}$ & 0.80 \\
\hline 5 & $\begin{array}{l}\text { I eat Aboriginal foods prepared } \\
\text { the traditional way }\end{array}$ & 0.59 & & Removed & \\
\hline 6 & $\begin{array}{l}\text { I participate in Aboriginal } \\
\text { cultural practices involving } \\
\text { music/dance }\end{array}$ & 0.83 & 4 & $\begin{array}{l}\text { I participate in Aboriginal } \\
\text { cultural practices involving musicl } \\
\text { dance (either traditional or } \\
\text { modern) }\end{array}$ & 0.80 \\
\hline 7 & $\begin{array}{l}\text { I participate in Aboriginal sports, } \\
\text { or play in an Aboriginal sports } \\
\text { team }\end{array}$ & 0.50 & & Removed & \\
\hline 8 & $\begin{array}{l}\text { I actively follow Aboriginal } \\
\text { sports, or follow Aboriginal } \\
\text { sports team } / \mathrm{s}\end{array}$ & 0.61 & & Removed & \\
\hline 9 & $\begin{array}{l}\text { I have received traditional } \\
\text { Aboriginal healing methods (e.g., } \\
\text { traditional healers, bush } \\
\text { medicine) }\end{array}$ & 0.78 & 5 & $\begin{array}{l}\text { Unchanged - I have received } \\
\text { traditional Aboriginal healing } \\
\text { methods (e.g., traditional healers, } \\
\text { bush medicine) }\end{array}$ & 0.80 \\
\hline 10 & $\begin{array}{l}\text { I spend time on Country (e.g., } \\
\text { living in homeland, travelling } \\
\text { through Country) }\end{array}$ & 0.89 & 6 & $\begin{array}{l}\text { Unchanged - I spend time on } \\
\text { Country (e.g., living in homeland, } \\
\text { travelling through Country) }\end{array}$ & 1.00 \\
\hline 11 & $\begin{array}{l}\text { I care for Country (e.g., burning } \\
\text { grass, cleaning up Country, fire } \\
\text { work) }\end{array}$ & 0.89 & 7 & $\begin{array}{l}\text { I care for Country (e.g., burning } \\
\text { grass, cleaning up Country, fire } \\
\text { work, conservation, regeneration) }\end{array}$ & 1.00 \\
\hline 12 & $\begin{array}{l}\text { I use Country and land (e.g., for } \\
\text { bush tucker, bush medicine, } \\
\text { hunting, fishing) }\end{array}$ & 0.94 & 8 & $\begin{array}{l}\text { Unchanged - I use Country and } \\
\text { land (e.g., for bush tucker, bush } \\
\text { medicine, hunting, fishing) }\end{array}$ & 1.00 \\
\hline 13 & $\begin{array}{l}\text { I protect Country (e.g., sacred } \\
\text { sites, animals, totems) }\end{array}$ & 1.00 & 9 & $\begin{array}{l}\text { Unchanged - I protect Country } \\
\text { (e.g., sacred sites, animals, } \\
\text { totems) }\end{array}$ & 1.00 \\
\hline 14 & $\begin{array}{l}\text { I participate in ceremony (e.g., } \\
\text { smoking ceremony, cleansing, } \\
\text { Corroboree) }\end{array}$ & 0.78 & 10 & $\begin{array}{l}\text { Unchanged - I participate in } \\
\text { ceremony (e.g., smoking } \\
\text { ceremony, cleansing, Corroboree) }\end{array}$ & 0.80 \\
\hline 15 & $\begin{array}{l}\text { I attend Aboriginal community } \\
\text { meetings }\end{array}$ & 0.83 & 11 & $\begin{array}{l}\text { I attendlparticipate in Aboriginal } \\
\text { community meetings }\end{array}$ & 1.00 \\
\hline
\end{tabular}


Table 1 (Continued)

\begin{tabular}{|c|c|c|c|c|c|}
\hline Item & Items in version two & CVI & $\begin{array}{l}\text { New } \\
\text { item }\end{array}$ & $\begin{array}{c}\text { Amendments made (Version } \\
3 \text { - Aboriginal Cultural } \\
\text { Engagement Survey) }\end{array}$ & CVI \\
\hline 16 & $\begin{array}{l}\text { I participate in social } \\
\text { engagements that include mostly } \\
\text { Aboriginal people }\end{array}$ & 0.83 & 12 & $\begin{array}{l}\text { I participate in social } \\
\text { engagements that are related to } \\
\text { Aboriginal people (e.g., NAIDOC } \\
\text { Week, Sorry Day events, } \\
\text { Knockout) }\end{array}$ & 1.00 \\
\hline 17 & $\begin{array}{l}\text { I participate in traditional } \\
\text { Aboriginal cultural activities } \\
\text { (e.g., Law time, NAIDOC Week, } \\
\text { Sorry Day events) }\end{array}$ & 0.94 & & $\begin{array}{l}\text { Removed (incorporated into new } \\
\text { item 12) }\end{array}$ & \\
\hline 18 & $\begin{array}{l}\text { I practice traditional and/or } \\
\text { contemporary Aboriginal } \\
\text { cultural relationships (e.g., } \\
\text { respect for Elders, avoidance } \\
\text { relationships, Law Men \& Law } \\
\text { Women) }\end{array}$ & 0.94 & & $\begin{array}{l}\text { Removed (incorporated into new } \\
\text { item 18) }\end{array}$ & \\
\hline 19 & $\begin{array}{l}\text { I respect the Elders' teaching of } \\
\text { traditional Law }\end{array}$ & 1.00 & 13 & $\begin{array}{l}\text { I respect the traditional teachings } \\
\text { of Elders }\end{array}$ & 1.00 \\
\hline 20 & $\begin{array}{l}\text { I spend time learning about } \\
\text { contemporary issues facing } \\
\text { Aboriginal people }\end{array}$ & 1.00 & 14 & $\begin{array}{l}\text { I spend time learning about issues } \\
\text { facing Aboriginal people today }\end{array}$ & 1.00 \\
\hline 21 & $\begin{array}{l}\text { I make contemporary Aboriginal } \\
\text { artworks }\end{array}$ & 0.62 & & $\begin{array}{l}\text { Removed (incorporated into new } \\
\text { item 2) }\end{array}$ & \\
\hline 22 & $\begin{array}{l}\text { I am aware of what Country I } \\
\text { belong to }\end{array}$ & 1.00 & 15 & $\begin{array}{l}\text { I am aware of what Country I } \\
\text { belong to and I acknowledge } \\
\text { where I am from }\end{array}$ & 1.00 \\
\hline 23 & $\begin{array}{l}\text { I feel I belong to land in a specific } \\
\text { area associated with my people }\end{array}$ & 1.00 & 16 & $\begin{array}{l}\text { Unchanged - I feel I belong to } \\
\text { land in a specific area associated } \\
\text { with my people }\end{array}$ & 1.00 \\
\hline 24 & $\begin{array}{l}\text { I have strong kinship links/family } \\
\text { links }\end{array}$ & 1.00 & 17 & $\begin{array}{l}\text { Unchanged - I have strong } \\
\text { kinship links/family links }\end{array}$ & 1.00 \\
\hline 25 & $\begin{array}{l}\text { I participate in traditional } \\
\text { Aboriginal cultural activities } \\
\text { (e.g., Law time, Men's and } \\
\text { Women's business, initiations, } \\
\text { burials) }\end{array}$ & 0.85 & 18 & $\begin{array}{l}\text { I participate in traditional } \\
\text { Aboriginal cultural activities } \\
\text { (e.g., Men's and Women's } \\
\text { business, burials) }\end{array}$ & 0.80 \\
\hline \multirow[t]{4}{*}{26} & $\begin{array}{l}\text { I participate in Aboriginal } \\
\text { community events (e.g., } \\
\text { NAIDOC Week, Sorry Day } \\
\text { Events, Knockout) }\end{array}$ & 0.93 & & $\begin{array}{l}\text { Removed (incorporated into new } \\
\text { item 12) }\end{array}$ & \\
\hline & & & 19 & $\begin{array}{l}\text { I feel I contribute to my } \\
\text { community (e.g., spending time } \\
\text { with Elders, going to community } \\
\text { events) }\end{array}$ & 1.00 \\
\hline & & & 20 & $\begin{array}{l}\text { My community accepts me as a } \\
\text { part of the Aboriginal community }\end{array}$ & 1.00 \\
\hline & & & 21 & I practise respect for Elders & 1.00 \\
\hline
\end{tabular}

Note: Items in italics form the final Aboriginal Cultural Engagement Survey. 
demonstrate a high level of expertise with regard to cultural engagement based on their contributions to the reference group and discussions. The experts included two community Elders, one staff member from the Aboriginal Medical Service, one staff member from the Aboriginal Health and Medical Research Council and one Aboriginal drug and alcohol worker. An I-CVI and scale level CVI (S-CVI; see Measures section) was calculated for the final revision based on the ratings of these five expert consultants.

\section{Measures}

\section{Content Validity Index}

Evaluating a scale's content validity is critical in establishing the construct validity of a new instrument (Haynes et al. 1995). Content validity refers to the extent to which an instrument has an appropriate sample of items to be representative of the phenomena of interest (Waltz et al. 1991). One of the most widely used methods of quantifying content validity is the CVI, a proportion agreement procedure based on expert ratings of relevance (Polit et al. 2007). The CVI can be calculated for each individual item on a scale (referred to as the I-CVI) and for the overall scale (the S-CVI). To calculate the I-CVI, experts are asked to rate the relevance of each item to Aboriginal cultural engagement on a four-point Likert scale (1-not relevant, 2-somewhat relevant, 3-quite relevant and 4-highly relevant). The I-CVI is the proportion of experts who assign a rating of quite relevant or highly relevant to the item (i.e., the number of experts rating the item as 3 or 4 divided by the number of experts) (Davis 1992, Polit et al. 2007). Polit et al. (2007) recommend that for an instrument to be judged as having excellent content validity, all items should have an I-CVI of 0.78 or higher. During a scale's development, it is recommended that items with an I-CVI of 0.78 should be considered relevant and be kept in the survey, while items just below this cut-off point should be considered for revision and items well below should be considered for deletion. It is also recommended that if a scale requires significant changes following one round of I-CVI calculations, a second round of expert ratings should be conducted with between three and five expert raters (Polit et al. 2007).

To compute the CVI for the overall scale (S-CVI), there are two common approaches. One is the universal agreement method, defined as the proportion of items on a scale that achieved a rating of 3 or 4 by all experts. The other is the average method, which involves computing the I-CVI for all items on the scale and then calculating the average across the items (Polit et al. 2007). These two methods can yield different values for the S-CVI. The average method, requiring an index of 0.90 or higher for excellent content validity, is recommended because the universal agreement approach is considered overly stringent and ignores the risk of chance agreement (Polit et al. 2007).

\section{Results}

\section{Content validity of version two}

Table 1 provides the I-CVI for each item in version two of the survey. Items with an I-CVI of 0.78 were kept in the survey, while items just below this cut-off point were 
considered for revision and items well below were deleted. A total of 18 respondents rated items 1 through 18 (13 consultants in the reference group and 5 consultants in telephone interviews prior to the reference group). Only 13 consultants rated items 19-26 since these items were new additions suggested by consultants in the stage two telephone interviews. The I-CVI for each item is included in Table 1, along with the amendments suggested by the reference group.

\section{Content validity of the Aboriginal Cultural Engagement Survey (ACES)}

Five consultants completed a CVI for each item in the final revision (version three) of the ACES. These I-CVI ratings are included in Table 1. The S-CVI was calculated using the S-CVI (average) method, and resulted in a value of 0.98 .

\section{Discussion}

The final 21 item version of the ACES had all I-CVI values above 0.78 and the S-CVI above 0.90 , suggesting excellent content validity. Aboriginal consultants were involved from the first to the last stage of the survey's development. This process was essential, and community involvement critical to both the inception and refinement of the survey items.

Development of items was a challenge even for members of the Aboriginal community. This was expressed and reflected in discussions in many ways, for example, a young female consultant within the reference group (stage three) expressed some difficulty in defining what Aboriginal culture was for her. This young woman explained that she lacked a culture which she could see, describe and practice, but that to her culture was evident in her own behaviour and the spirit with which she was accepted within her community. Many members of the reference group discussed this loss of a definable culture within the younger generations, and stated this to be in part due to the older generations' loss of knowledge, shame in their own Aboriginal culture and unwillingness to practice traditional culture for the fear that it may be 'sold-out' by non-Aboriginal Australians. Items 19, 20 and 21 were suggested by this young woman and others in the reference group in an attempt to capture the more difficult to define 'culture' for younger generations.

Australian Aboriginal culture is known to be extremely diverse, and at many times throughout the development process the researchers were advised by Aboriginal individuals of the significant difficulty in developing a measure relevant to all Aboriginal Australians. It is acknowledged by the researchers that this survey may have limits with some Aboriginal cultures far removed from the semi-urban population with whom this survey was validated. However, it is hoped that by including Aboriginal individuals and community members from many different regions and backgrounds in this process, the ACES is sufficiently general to be of use in most contexts. It should be reiterated that the ACES is not expected to capture cultural engagement for every Aboriginal individual. Those who do not endorse items on the ACES are in no way considered to be un-Aboriginal or to have a deficit of culture, and those administering the survey should remain aware of the complexity and diversity of cultural identity and its expression when considering an individual's responses on the ACES. 
In stages two and three there was an imbalance between male and female consultants. Although efforts were made by researchers to minimise this imbalance, the final group of consultants in stage two included four males and one female and the consultants in stage three included 11 females and two males. This may affect the generalisability of the items to both genders. However, the overall number of individual consultants across all four stages included 9 males and 13 females (with consultants who participated in more than one stage only counted as one consultant). Therefore it is hoped that any gender bias has been minimised by the overall number of participants in each gender differing only slightly.

The ACES is a new scale which takes an important step in capturing and measuring cultural engagement for Aboriginal Australians, with the hope of providing more culturally appropriate health services in the future. However, this hope is based on the premise that enhancing cultural engagement for Aboriginal Australians will actually bring about positive change. While this assertion may make sense in theory, there is currently very little evidence to support this. There is a need to measure more directly the relationship between engagement in cultural activities and health outcomes. By using the ACES to establish the level of cultural engagement of individuals over time, researchers may compare this engagement with outcomes within health services to determine the effects of cultural engagement. Establishing a link between cultural engagement and positive health outcomes may provide a theoretical basis for the inclusion of culture in treatment planning and programme development. Future research may indicate whether health benefits are seen within specific areas of Australian health services, such as substance abuse services. In addition, further research may investigate whether engagement in specific types of cultural activities is especially beneficial for Aboriginal clients of health services, and whether engagement in such activities may lead to specific health and psychological benefits.

Future studies now need to assess other elements of reliability and validity of the ACES. For example, predictive validity may be especially important to investigate within Australian Aboriginal health services. The extent to which engagement and involvement in cultural activities predicts better health outcomes for Aboriginal clients is important for service development.

\section{Key messages}

(1) The ACES is a new measure for use with Australian Aboriginal populations.

(2) This scale has been found to have excellent content validity.

(3) The ACES shows promise for being a useful tool in assessing the cultural engagement of Aboriginal clients, which may then be used to measure the association between cultural engagement and health outcomes.

(4) The establishment of a clear relationship between cultural engagement and positive health benefits will assist in designing future interventions which better meet the cultural needs of Aboriginal Australians within health services.

\section{Acknowledgements}

This research was partly funded through the NSW Health Drug and Alcohol Research Grants Program. 


\section{References}

Anderson, P., 1996. Priorities in aboriginal health. In: G. Robinson, ed. Aboriginal health, social and cultural transitions: proceedings of a conference, 29-31 September, 1995, The Northern Territory University, Darwin. Darwin: NTU Press, 15-18.

Berry, S.L. and Crowe, T.P., 2009. A review of engagement of Indigenous Australians within mental health and substance abuse services. Australian e-Journal for the Advancement of Mental Health, 8 (1), 16-27.

Burgess, C.P., et al., 2008. Development and preliminary validation of the 'Caring for Country' questionnaire: measurement of an aboriginal Australian health determinant. International Journal for Equity in Health, 7 (26), Available from: http://www.equityhealthj. com/content/7/1/26 [Accessed 13 December 2011].

Cleworth, S., Smith, W., and Sealey, R., 2006. Grief and courage in a river town: a pilot project in the Aboriginal Community of Kempsey, New South Wales. Australasian Psychiatry, 14 (4), 390-394.

Commonwealth Secretariat, 2007. Report of the Commonwealth Commission on respect and understanding. London: Commonwealth Secretariat.

Davis, L.L., 1992. Instrument review: getting the most from a panel of experts. Applied Nursing Research, 5 (4), 194-197.

Haynes, S., Richard, D., and Kubany, E., 1995. Content validity in psychological assessment: a functional approach to concepts and methods. Psychological Assessment, 7 (3), 238-247.

Hunter, E., 1993. Aboriginal health and history. Power and prejudice in remote Australia. Melbourne: Oxford University Press.

Johnson, T.P. and Bowman, P.J., 2003. Cross-cultural sources of measurement error in substance use surveys. Substance Use and Misuse, 38 (10), 1447-1490.

Kingsley, J., et al., 2009. "If the land is healthy ... it makes the people healthy": the relationship between caring for country and health for the Yorta Yorta Nation, Boonwurrung and Bangerang Tribes. Health \& Place, 15 (1), 291-299.

Kirk, D.H. and Goon, S., 1975. Desegregation and the Cultural Deficit Model: an examination of the literature. Review of Educational Research, 45 (4), 599-611.

Leenaars, A.A., et al., 1999. Genocide and suicide among Indigenous people: The North meets the South. Canadian Journal of Native Studies, 19 (2), 337-363.

McDermott, R., et al., 1998. Beneficial impact of the Homelands Movement on health outcomes in central Australian Aborigines. Australia and New Zealand Journal of Public Health, 22 (6), 653-658.

Morice, R., 1976. Woman dancing woman dreaming: psychological benefits of the Aboriginal outstation movement. Medical Journal of Australia, 2, 939-942.

O’Dea, K., 1984. Marked improvement in carbohydrate and lipid metabolism in diabetic Australian Aborigines after temporary reversion to traditional lifestyle. Diabetes, 33 (6), 596-603.

Phinney, J.S., 1992. The multigroup ethnic identity measure: a new scale for use with diverse groups. Journal of Adolescent Research, 7 (2), 156-176.

Polit, D.F., Beck, C.T., and Owen, S.V., 2007. Is the CVI an acceptable indicator of content validity? Appraisal and recommendations. Research in Nursing \& Health, 30 (4), 459-467.

Rowley, K., et al., 2008. Lower than expected morbidity and mortality for an Australian Aboriginal population: 10-year follow-up in a decentralised community. Medical Journal of Australia, 188 (5), 283-287.

Torres Stone, R.A., et al., 2006. Traditional practices, traditional spirituality, and alcohol cessation among American Indians. Journal of Studies on Alcohol, 67 (2), 236-244.

Waltz, C.F., Strickland, O., and Lenz, E., 1991. Measurement in nursing research. 2nd ed. Philadelphia: F.A. Davis.

Westerman, T., 2004. Engagement of Indigenous clients in mental health services: What role do cultural differences play? Australian e-Journal for the Advancement of Mental Health, $3(3), 1-6$.

Westerman, T., 2008. Mental health assessment of Aboriginal clients. Nowra, NSW: Workshop presentation.

Ypinazar, V.A., et al., 2007. Indigenous Australians' understandings regarding mental health and disorders. Australian and New Zealand Journal of Psychiatry, 41 (6), 467-478. 